OPEN ACCESS

Edited by:

Sead Sabanadzovic,

Mississippi State University,

United States

Reviewed by:

Jiatao Xie,

Huazhong Agricultural University,

China

Sotaro Chiba

Nagoya University, Japan

*Correspondence:

Encarnación Pérez-Artés eperezartes@ias.csic.es

Specialty section:

This article was submitted to

Virology,

a section of the journal

Frontiers in Microbiology

Received: 22 July 2019 Accepted: 24 December 2019

Published: 24 January 2020

Citation:

Torres-Trenas A, Cañizares MC,

García-Pedrajas MD and

Pérez-Artés E (2020) Molecular and Biological Characterization of the First Hypovirus Identified in Fusarium

oxysporum

Front. Microbiol. 10:3131 doi: 10.3389/fmicb.2019.03131

\section{Molecular and Biological Characterization of the First Hypovirus Identified in Fusarium oxysporum}

\author{
Almudena Torres-Trenas ${ }^{1,2}$, M. Carmen Cañizares², M. Dolores García-Pedrajas ${ }^{2}$ and \\ Encarnación Pérez-Artés ${ }^{1 *}$ \\ 'Departamento de Protección de Cultivos, Instituto de Agricultura Sostenible, Consejo Superior de Investigaciones \\ Cientificas, Córdoba, Spain, ${ }^{2}$ Instituto de Hortofruticultura Subtropical y Mediterránea "La Mayora", Universidad de Málaga, \\ Consejo Superior de Investigaciones Cientificas, Málaga, Spain
}

A novel mycovirus named Fusarium oxysporum f. sp. dianthi hypovirus 2 (FodHV2) has been identified infecting isolates Fod 408 and Fod 409 of Fusarium oxysporum f. sp. dianthi from Morocco. The genome of FodHV2 is 9,444 nucleotides long excluding the poly $(A)$ tail, and has a single open reading frame encoding a polyprotein. The polyprotein contains three highly conserved domains of UDP glucose/sterol glucosyltransferase, RNA-dependent RNA polymerase, and viral RNA helicase. In addition, particular residues of Cys, Hys, and Gly detected in the N-terminal region suggest the presence of the catalytic site of a highly diverged papain-like protease. Genomic organization, presence of particular conserved motifs, and phylogenetic analyses based on multiple alignments clearly grouped FodHV2 with the members of the family Hypoviridae. FodHV2 was transferred by hyphal anastomosis to a recipient Hyg $^{\mathrm{R}}$-tagged virus-free strain. The comparison of the infected and non-infected isogenic strains showed that FodHV2 did not alter the vegetative growth, neither the conidiation nor the virulence of its fungal host. Efficiency of FodHV2 transmission through the conidia was $100 \%$ in both the original and the recipient infected-isolates. To the best of our knowledge, this is the first report of a hypovirus infecting the plant pathogen $F$. oxysporum, and also the first one of a hypovirus detected in a fungal strain from the African continent.

Keywords: hypovirus, FodHV2, Fusarium oxysporum, Hypoviridae, mycovirus

\section{INTRODUCTION}

The soilborne fungal species Fusarium oxysporum contains a diversity of host-plant specific forms (formae speciales) that cause vascular diseases in a large number of economically important crops. F. oxysporum f. sp. dianthi is the forma specialis that infects carnation, causing the most severe disease in this crop worldwide (Garibaldi and Gullino, 1987; Baayen et al., 1997). The control of vascular wilt of carnation has been tried mainly by applying soil fumigants such as methyl bromide before planting, together with the use of resistant varieties. However, the recent prohibition on 
the use of methyl bromide, together with the difficulty in obtaining carnation varieties resistant to the different pathogenic variants (races) of the fungus, made control of this disease ineffective. Alternatively, methods based on the addition to the soil of organic amendments such as poultry manure or pepper compost, followed by soil solarization, were developed and applied with variable success (Melero-Vara et al., 2011).

Mycoviruses (viruses that infect fungi) are found in all major groups of phytopathogenic fungi (reviewed in Ghabrial and Suzuki, 2009; Pearson et al., 2009; Son et al., 2015). Most mycoviruses possess either single-stranded or double-stranded RNA genomes. A recent in silico study analyzing transcriptome datasets from fungi has revealed an unknown frequency and diversity of viral infections (Gilbert et al., 2019). Viral infections are frequently cryptic, but in some cases an alteration of particular phenotypic fungal traits, including virulence, can be observed. The use of hypovirulence-associated mycoviruses has been proposed as a new strategy for biological control (virocontrol) of fungal diseases (Chiba et al., 2009; Ghabrial and Suzuki, 2009). The most studied case is that of Cryphonectria hypovirus 1 (CHV1), a mycovirus in the family Hypoviridae that has been successfully used for the control of chestnut blight caused by Cryphonectria parasitica in Europe (Milgroom and Cortesi, 2004; Nuss, 2005). Currently recognized hypoviruses, Crypohonectria hypovirus 1-4 (CHV1, CHV2, CHV3, CHV4), were all isolated from the chestnut blight fungus C. parasitica (Fulbright, 1984; Shapira et al., 1991; Hillman et al., 1992, 1994; Smart et al., 1999; Hillman et al., 2000; Yuan and Hillman, 2001; LinderBasso et al., 2005), and are classified into four homonymous species in the genus Hypovirus, family Hypoviridae. Success in using $\mathrm{CHV} 1$ for the biological control of chetnust blight has prompted interest in identifying new members of this family in other phytopathogenic species. Consequently, a number of novel related viruses were isolated from different phytopathogenic fungi, including Alternaria alternata hypovirus 1 (AaHV1; Li et al., 2019), Botrytis cinerea hypovirus 1 (BcHV1; Hao et al., 2018), Entoleuca Hypovirus 1 (EnHV1; Velasco et al., 2018), Phomopsis longicolla hypovirus 1 (PlHV1; Koloniuk et al., 2014), Rosellinia necatrix hypovirus 1 and 2 (RnHV1 and RnHV2; Arjona-Lopez et al., 2018; Velasco et al., 2018), Sclerotinia sclerotiorum hypovirus 1 and 2 (SsHV1 and SsHV2; Xie et al., 2011; Hu et al., 2014), Setosphaeria turcica hypovirus 1 (StHV1; Gilbert et al., 2019), and Valsa ceratosperma hypovirus 1 (VcHV1; Yaegashi et al., 2012). In the genus Fusarium, four putative members of the family Hypoviridae have been identified: Fusarium graminearum hypovirus 1 (FgHV1) from F. graminearum strain HN10 (Wang et al., 2013), Fusarium graminearum hypovirus 2 (FgHV2) from $F$. graminearum strain SJ16 (Li et al., 2015), Fusarium poae hypovirus 2 (FpHV2) from F. poae strain MAFF 240374 (Osaki et al., 2016), and Fusarium langsethiae hypovirus 1 (FlHV1) from F. langsethiae strain AH32 (Li et al., 2017). All the above-mentioned viruses have not yet been approved by the International Committee of Taxonomy for Viruses (ICTV) as members of the family Hypoviridae (Suzuki et al., 2018).

All recognized hypoviruses are non-encapsidated, positive single-stranded RNA viruses. The genomes of hypoviruses range from 9 to 14 kilobase $(\mathrm{kb})$ in length excluding a poly $(\mathrm{A})$ tail, and possess one or two open reading frames (ORFs) on their coding strands. Genomic sequences of all hypoviruses contain conserved domains of a papain-like protease, an RNA-dependent RNA polymerase (RdRp), and an RNA helicase (Suzuki et al., 2018). Depending on the presence of either one or two ORFs, and also based on genomic characteristics and phylogenetic analyses, the viral family Hypoviridae has been recently proposed to be divided into two ("Alphahypovirus" and "Betahypovirus") (Yaegashi et al., 2012; Khalifa and Pearson, 2014; Li et al., 2015), or three (“Alphahypovirus," "Betahypovirus," and "Gammahypovirus") (Hu et al., 2014) genera.

Despite its denomination, infection by a hypovirus does not always result in the induction of hypovirulence in its fungal host. Virulence levels among different hypoviruses vary considerably. For example, among the four hypoviruses identified infecting different strains of $\mathrm{C}$. parasitica, $\mathrm{CHV} 1$ and $\mathrm{CHV} 2$ alter fungal growth and strongly reduce fungal virulence (Hillman et al., 1990, 1992, 1994). On the other side, CHV3 has little effect on fungal growth while also reduces substantially the virulence of C. parasitica (Fulbright, 1984; Smart et al., 1999), and CHV4 has not observable effect on its host (Enebak et al., 1994; Linder-Basso et al., 2005). In the case of hypoviruses identified in Fusarium species, only the hypovirus detected in F. graminearum isolate SJ16 (FgHV2) has been associated with hypovirulence (Li et al., 2015), whereas FgHV1 does not alter the virulence of its host (Wang et al., 2013), and the possible effect of FlHV1 or FpHV2 has not been reported.

In this work we describe and biologically characterize a putative novel virus in the family Hypoviridae, for which we proposed the name Fusarium oxysporum f. sp. dianthi hypovirus 2 (FodHV2). It is the first hypovirus identified in the species F. oxysporum.

\section{MATERIALS AND METHODS}

\section{Fungal Isolates and Culture Conditions}

Strains of F. oxysporum f. sp. dianthi used in this study were isolated in 2012 from soil samples and diseased carnation plants collected in a carnation-growing area in Morocco (Table 1). All isolates were characterized to race and molecular group using multiplex-PCR, as previously described (Gómez-Lama Cabanás et al., 2012). Isolates were stored at $-80^{\circ} \mathrm{C}$ in glycerol, and propagated on potato dextrose agar (PDA) medium at $25^{\circ} \mathrm{C}$ in the dark.

\section{dsRNA Purification}

Viral dsRNA was purified by cellulose column chromatography (Valverde et al., 1990) from the mycelium collected after 7 days of growth in potato dextrose broth, as previously described (Lemus-Minor et al., 2018). The purified dsRNA extracts were analyzed by electrophoresis in $0.8 \%$ agarose gels stained with RedSafe ${ }^{\mathrm{TM}}$ Nucleic Acid Staining Solution (iNtRON Biotechnology, Seongnam-si, South Korea). The dsRNA nature of the extracts was confirmed by digestion with DNase I and RNase A treatment in low salt condition. 
TABLE 1 | Fusarium oxysporum f. sp. dianthi isolates analyzed.

\begin{tabular}{lcc}
\hline Isolate (s) $^{(\mathbf{a})}$ & Source & $\begin{array}{c}\text { Race group } \\
\text { assignation by } \\
\text { PCR pattern }\end{array}$ \\
\hline Fod $406,407,409,410,411,412,424,425$ & Plant & R1t \\
Fod 413, 414, 416, 417, 418, 419, 421,422, & Soil & R1t \\
426, 427, 428, 429, 430, 431, 432 & R2II \\
Fod 415, 420, 423 & Soil & R2II \\
Fod 408 & Plant & \\
\hline
\end{tabular}

(a) All isolates were from Morocco. (b) Race assignation by multiplex specific-PCR amplifications, as described in Gómez-Lama Cabanás et al. (2012). R1t = race 1 type, $R 2 \|$ = race 2 molecular group $/$.

\section{cDNA Synthesis, Cloning, Sequencing, and Phylogenetic Analysis}

The complete sequence of the viral RNA was determined using a combination of techniques as reverse transcription (RT), polymerase chain reaction (PCR) amplifications, cloning and Sanger sequencing. RT and PCR amplifications were performed using random hexamer priming, and amplified products were cloned into the vector pCR Blunt (Invitrogen, Carlsbad, CA, United States) and sequenced. Analysis of these partial nucleotide sequences with the BLASTX algorithm in the NCBI database arranged them according to a high sequence similarity with other mycoviruses. Specific primers were then designed to fill in the sequence gaps. Clones for the terminal sequences of the dsRNA were generated by Single Primer Amplification Technique (SPAT), using T4 RNA ligase oligonucleotide-mediated amplification (Xie et al., 2006). Assembly of these sequences was performed using the software Lasergene SeqMan ${ }^{\text {TM }}$ Version 7.0.0 (DNASTAR ${ }^{\circledR}$ Inc., Madison, WI, United States). For comparison of the nucleotide sequences of the $5^{\prime}$ - and $3^{\prime}$ UTRs, and the amino acid (aa) sequences of conserved domains, multiple sequence alignments were carried out using the software MAFFT version 7 with the default parameters (Katoh and Standley, 2013). Phylogenetic trees were constructed using the program Tree View of Geneious 8.1.5 package (Biomatters), and generated by the NeighborJoining (NJ) method (Saitou and Nei, 1987) with 1000 bootstrap replicates.

\section{Virus Detection}

Infection of fungal isolates with FodHV2 was tested by performing a RT-PCR on denatured dsRNAs using specific primers directed to the RdRp sequence of FodHV2. Primers FodHV2RT (5'-CAGGGACTACAGGTAAAGT-3') and FodH V2F/FodHV2R (5'-GGAAGTTGGTGGAGGAGCTG-3'/5'-GT ACTTTTGTGCTTCTTCCAGG-3') were used for the RT and the PCR, respectively. The products of the RT-PCR amplifications were analyzed by electrophoresis in $1.5 \%$ agarose gels. All resulting amplicons were purified from the gel, sequenced and analyzed for homology with the sequence of FodHV2 using the program Geneious version 8.1.5 (Biomatters).

\section{Virus Transmission}

To analyze the effect of FodHV2 on its fungal host, two isogenic fungal isolates, infected and not infected with the mycovirus, were compared. We first attempted to obtain the isogenic versions by selecting single conidia from the originally infected isolate Fod 408. Selection of the conidia was performed as described (Lemus-Minor et al., 2019), and the dsRNA extracts of the resulting monoconidial cultures were analyzed by cellulose column chromatography to check for the presence of FodHV2 dsRNA. In another approach, FodHV2 was transmitted by hyphal anastomosis from the strain originally infected (Fod 408, donor), to another virus-free strain that had been previously transformed with a hygromycin resistance gene (Fod $77 \mathrm{Hyg}^{\mathrm{R}}$, recipient), as described in LemusMinor et al. (2019). Presence of FodHV2 in recipient isolate Fod $77 \mathrm{Hyg}^{\mathrm{R}}$ was confirmed by dsRNA extraction and RTPCR. In addition, efficiency in virus transmission through the spores in the new infected isolate Fod $77 \mathrm{Hyg}^{\mathrm{R}}$ was also determined.

\section{Effect of FodHV2 on Selected Phenotypic Traits of Its Fungal Host}

The effect of FodHV2 on its fungal host was analyzed by determining differences in mycelial growth rate between the virus-free $\left(\right.$ Fod $\left.77 \mathrm{Hyg}^{\mathrm{R}}\right)$ and the virus infected (Fod $77 \mathrm{Hyg}^{\mathrm{R}} \mathrm{HV}^{+}$) isolates on solid medium, conidiation rate in liquid medium, and virulence on carnation. To determine the effect of FodHV2 on mycelial growth rate, 100 conidia of each isolate were placed in the center of a PDA plate (three replicates), and the growth area was measured daily as previously described (Lemus-Minor et al., 2018). To analyze the effect of FodHV2 on the conidiation rate in liquid medium, 200 conidia $/ \mathrm{ml}$ of each isolate were added to $5 \mathrm{ml}$ of casein-hydrolyzed medium with AZ solution (three replicates). The cultures were incubated, and the conidia were counted at different times (Lemus-Minor et al., 2018). Data, growth area and conidia. $\mathrm{ml}^{-1}$, were used to do an analysis of variance (ANOVA). Significant differences among means for daily values of growth area or conidiation obtained with each isolate were determined using Tukey's honest significant difference (HSD; $P \leq 0.01$ ) test. To determine the effect of FodHV2 on the virulence, isolates Fod $77 \mathrm{Hyg}^{\mathrm{R}}$ or Fod $77 \mathrm{Hyg}^{\mathrm{R}} \mathrm{HV}^{+}$were inoculated on five different carnation cultivars, the resistant cultivar Galaxia and the susceptible cultivars Baltico, Candela, Master and Pink Bijou. Obtaining of inoculum, inoculation of carnation cuttings, and greenhouse conditions were as previously described (Gómez-Lama Cabanás et al., 2012). Plants of each cultivar treated with water were used as controls. Fusarium wilt symptoms were evaluated every 2 days for approximately 3 months using a scale of disease from 0 (no symptoms) to 5 (dead plant). Disease severity values were used to calculate the percentage of the standardized area under the disease progress curve (sAUDPC). ANOVA was used to analyze sAUDPC percentages. Significant differences among means for disease severity values with each isolate were determined using the Fisher's least significant difference (LSD; $P \leq 0.05$ ). This test of virulence was repeated two times. 
At the end of each pathogenicity test, two plants inoculated with each Fod $77 \mathrm{Hyg}^{\mathrm{R}}$ or Fod $77 \mathrm{Hyg}^{\mathrm{R}} \mathrm{HV}^{+}$were used to reisolate the fungus, as described in Lemus-Minor et al. (2018). Stem sections from the selected carnation plants were placed on V8 agar plates (Komada, 1975) and incubated at $25^{\circ} \mathrm{C}$ in the dark. Mycelia from the fungal colonies obtained were analyzed by cellulose column chromatography to confirm presence or absence of mycovirus FodHV2.

\section{RESULTS}

\section{Detection of Viral dsRNA in $F$. oxysporum f. sp. dianthi}

A total of 27 Fusarium oxysporum f. sp. dianthi (Fod) isolates, all of them obtained from carnation plants and soil samples from Morocco, was used in this work (Table 1). The isolates were first characterized by multiplex-PCR and determined to belong to two different races-molecular groups (Table 1), and then subjected to dsRNA purification by cellulose column chromatography. Direct observation of the dsRNA extracts showed the presence of two potentially viral dsRNA molecules in isolates Fod 408 and Fod 409 (Figure 1). The two dsRNA bands had estimated sizes of $\sim 9.5 \mathrm{kbp}$ (dsRNA-1) and $\sim 3.0 \mathrm{kbp}$ (dsRNA-2), respectively. Both segments were confirmed to be dsRNA in nature based on its resistance to digestion with DNase I, but susceptibility to degradation by RNase A treatment (Supplementary Figure 1). We selected isolate Fod 408 to characterize the dsRNA elements identified.

\section{Molecular Characterization of a Novel Mycovirus Infecting F. oxysporum f. sp. dianthi}

A total of 96 clones were obtained and sequenced. Every region of the genome was determined by sequencing of at least five independent clones. The amplification of a specific PCR product using an oligo-dT primer demonstrated that the dsRNA molecule contained a poly(A) tail at the $3^{\prime}$-terminus of its positive strand. The complete genome sequence was determined to be $9,444 \mathrm{nt}$ in length, excluding the poly(A) tail. Only six partial sequences were obtained for the $\sim 3.0 \mathrm{~kb}$ dsRNA-2 segment. Although these sequences showed a variable nt identity (between 41 and $81 \%$ ) exclusively with the corresponding nt sequences in dsRNA-1, the exact nature of this dsRNA-2 has not been confirmed (not shown).

A homology search with the nt sequence using the BlastX program showed significant similarities (e-value of $<0.01$ ) between the deduced aa sequence and the polyprotein of Cryphonectria hypovirus 4 (CHV4/SR2), Valsa ceratosperma hypovirus 1 (VcHV1/MVC86), Phomopsis longicolla hypovirus 1 (PlHV1/ME711), Cryphonectria hypovirus 3 (CHV3/GH2), Botrytis cinerea hypovirus 1 (BcHV1/HBstr-470), Setosphaeria turcica hypovirus 1 (StHV1/28A), Sclerotinia sclerotiorum hypovirus 1-A (SsHV1-A), and Sclerotinia sclerotiorum hypovirus 1 (SsHV1/SZ-150). The aa identities with these sequences ranged between 45 and 61\% (Table 2). The coding sequence was flanked by two untranslated regions (UTR) of 309

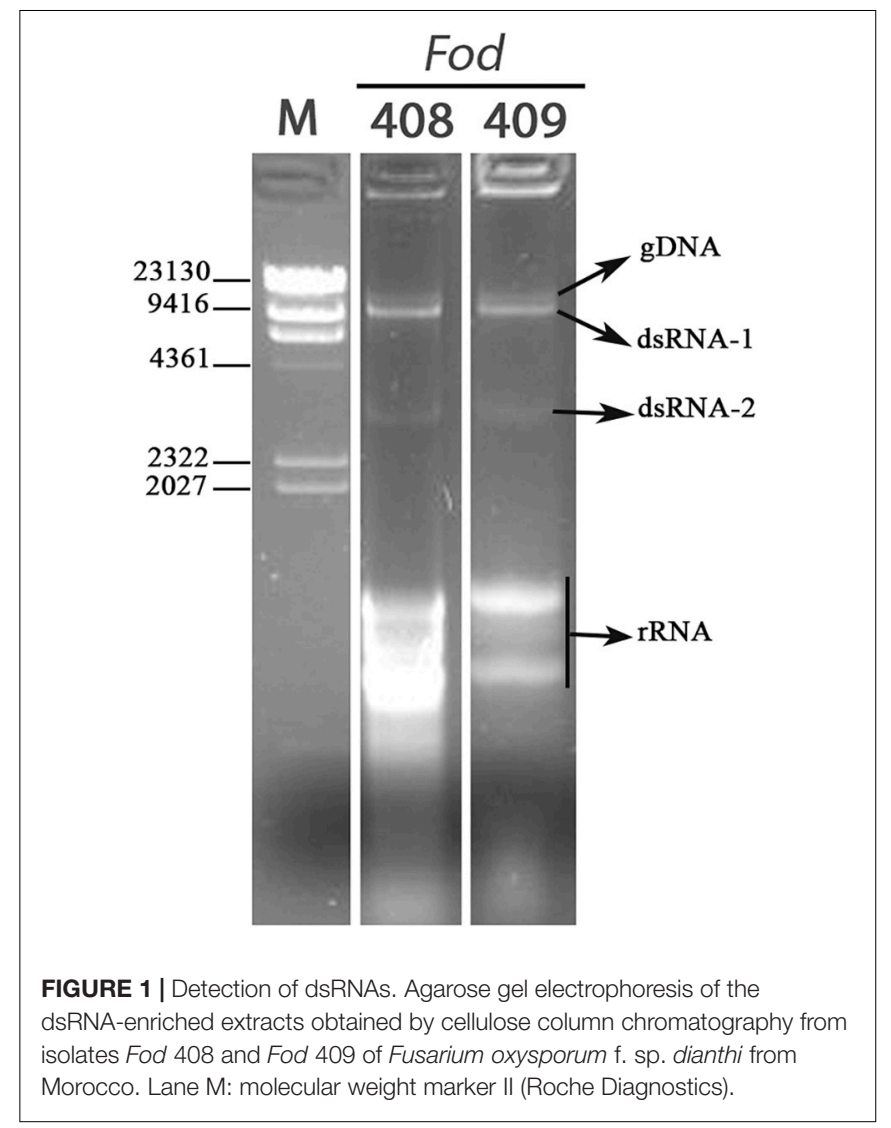

nt at the $5^{\prime}$ end (nt 1-309) and 456 nt at the $3^{\prime}$ terminus (nt $8,988-9,444)$ excluding the poly(A) tail. The first $100 \mathrm{nt}$ of the $5^{\prime}$-UTR and the last $100 \mathrm{nt}$ of the $3^{\prime}$-UTR showed high identities with those of the above-cited hypoviruses (Figure 2A). This result indicated that this mycovirus could be a new member of the Hypoviridae family, that we tentatively named Fusarium oxysporum $\mathrm{f}$. sp. dianthi hypovirus 2 (FodHV2).

Sequence analysis revealed that FodHV2 has a single 8,679 nt long ORF in the positive strand, that starts with the AUG codon in the position 310 and finishes with the UAG codon in the position 8,988 . This sequence encodes a polyprotein of 2,892 aa residues with a predicted molecular mass of $268 \mathrm{kDa}$. The deduced aa sequence of the polyprotein contains highly conserved domains of UDP glucose/sterol glucosyltransferase (UGT), RNA-dependent RNA polymerase (RdRp), and viral RNA helicase (Hel). In addition, conserved Cys (Cys $\left.{ }^{339}\right)$, Hys $\left(\mathrm{Hys}^{400}\right)$, and Gly $\left(\mathrm{Gly}^{423}\right)$ residues in the $\mathrm{N}$-terminal region of the polyprotein could represent the catalytic site of a highly diverged papain-like protease (Figure 2B).

The UGT domain (nt 1,666-2,925) is 420 aa in length. Alignment of the aa sequence of this UGT domain with that of other mycoviruses in the Hypoviridae family identified the four highly conserved motifs (CM-1 to 4; Figure 3 ) as previously described (Warnecke et al., 1999). Downstream from the UGT domain (nt 5,785-6,707) a 308 aa long RdRp domain with the highly conserved motifs $\mathrm{A}, \mathrm{B}$, and $\mathrm{C}$ that form the catalytic center of this enzyme was identified. In particular the motif $\mathrm{C}$ was 
TABLE 2 | Results from BLASTX homology search with Fusarium oxysporm f. sp. dianthi hypovirus 2 (FodHV2).

\begin{tabular}{|c|c|c|c|c|c|c|c|}
\hline Virus $^{a}$ & Acronym & $\begin{array}{l}\text { Protein } \\
\text { (aa size) }\end{array}$ & $\begin{array}{c}\text { Overlap } \\
\text { (aa identities \%) }\end{array}$ & $\begin{array}{c}\text { Bit score/ } \\
\text { e-value }\end{array}$ & $\begin{array}{c}\text { GenBank } \\
\text { accesion no. }\end{array}$ & $\begin{array}{l}\text { Query } \\
\text { cover }\end{array}$ & $\begin{array}{c}\text { GenBank } \\
\text { accesión no. }\end{array}$ \\
\hline Cryphonectria hypovirus 4 & CHV4/SR2 & Polyprotein (2848) & $1444 / 2862(50)$ & 2578/0.0 & AY307099 & $88 \%$ & AY307099 \\
\hline Valsa ceratosperma hypovirus 1 & VcHV1/MVC86 & Polyprotein (2940) & $1354 / 2889(47)$ & $2505 / 0.0$ & AB690372 & $90 \%$ & AB690372 \\
\hline Phomopsis longicolla hypovirus 1 & PIHV1/ME711 & Polyprotein (2848) & $1212 / 2479(49)$ & $2286 / 0.0$ & KF537784.1 & $87 \%$ & KF537784.1 \\
\hline Cryphonectria hypovirus 3 & $\mathrm{CHV} 3 / \mathrm{GH} 2$ & Polyprotein (2874) & $1198 / 2550(47)$ & $2220 / 0.0$ & AF188515 & $80 \%$ & AF188515 \\
\hline Botrytis cinerea hypovirus 1 & BcHV1/HBtom372 & Polyprotein (2964) & $1181 / 2523(47)$ & $2155 / 0.0$ & MG554632.1 & $81 \%$ & MG554632.1 \\
\hline Setosphaeria turcica hypovirus 1 & StHV1/28A & Polyprotein (2751) & 1090/1785 (61) & $2141 / 0.0$ & MK279474.1 & $77 \%$ & MK279474.1 \\
\hline Sclerotinia sclerotiorum hypovirus 1-A & SsHV1-A & Polyprotein (2943) & $1132 / 2515(45)$ & $2115 / 0.0$ & AWY10948 & $80 \%$ & AWY10948 \\
\hline Sclerotinia sclerotiorum hypovirus 1 & SsHV1/SZ-150 & Polyprotein (2948) & $1131 / 2520(45)$ & $2103 / 0.0$ & AEL99352 & $80 \%$ & AEL99352 \\
\hline
\end{tabular}

aThe top eight distinct viruses returned by BlastX are shown.

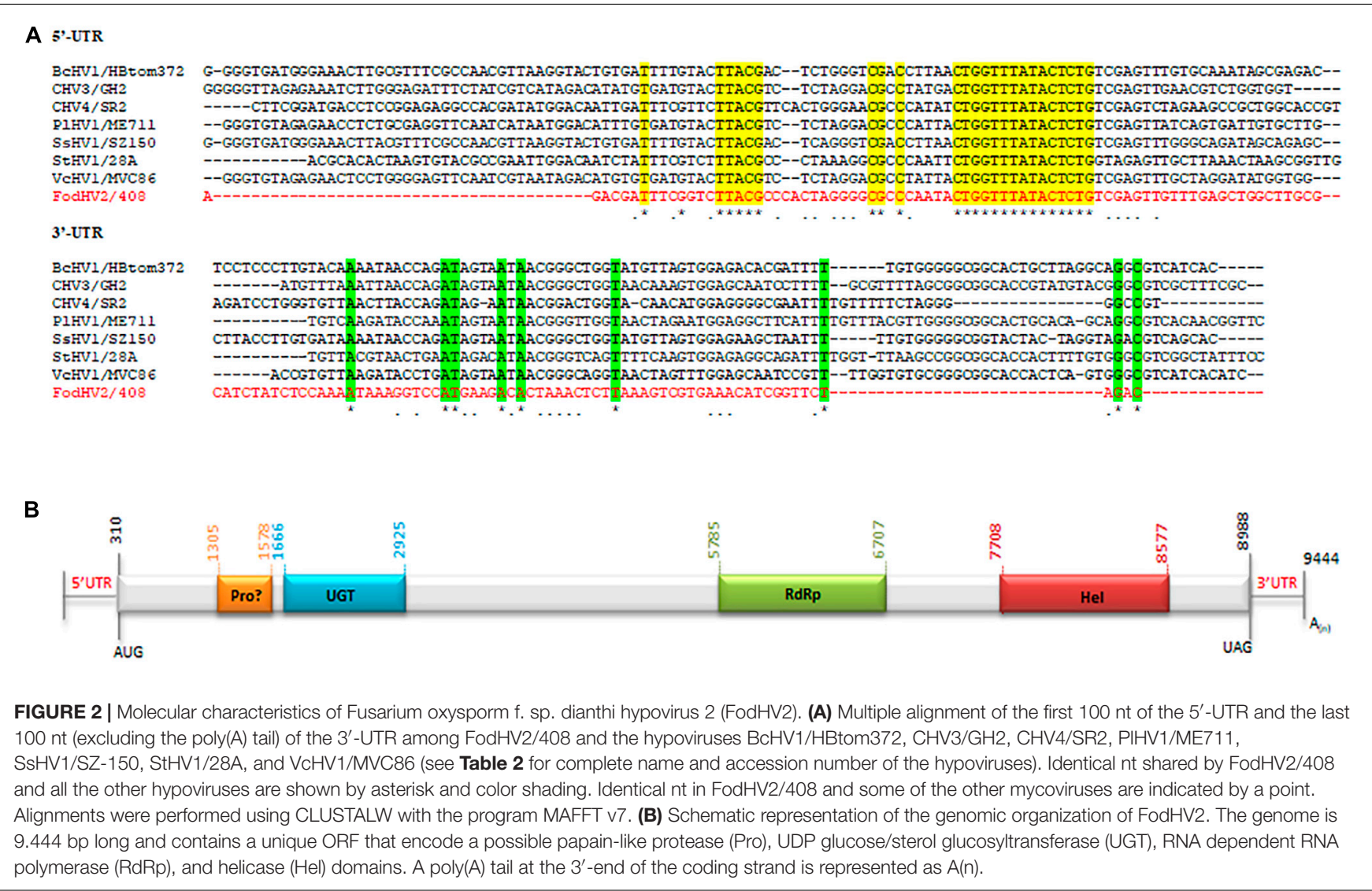

constituted by the SDD tripeptide, which is present in RdRps encoded by most of the Hypoviridae members (Hansen et al., 1997; O’Reilly and Kao, 1998; Gohara et al., 2000) (Figure 4A). Finally, a helicase domain of 290 aa was identified at the C-terminal region (nt 7708-8577). This Hel domain contained six out of the eight conserved motifs that constitute the DEAD, DEAH, and DEXH boxes characteristic of the RNA Helicases in the Superfamily II (Linder et al., 1989) (Figure 4A). This genomic organization is similar to that described for viruses belonging to the genus Hypovirus, suggesting that FodHV2 is a new member of the family Hypoviridae. The complete sequence has been deposited in the GeneBank database under the accession number MN176979.

\section{Phylogenetic Relationship Between FodHV2 and Other Hypoviruses}

To understand the phylogenetic relationship between FodHV2 and other members in the family Hypoviridae, a phylogenetic analysis based on the Neighbor-Joining method was performed using the full-length aa sequence of the viral polyprotein. Result obtained distributed hypoviruses into the three distinct phylo groups corresponding to proposed genera of "Alphahypovirus," "Betahypovirus," and "Gammahypovirus" (Yaegashi et al., 2012; Hu et al., 2014; Khalifa and Pearson, 2014; Li et al., 2015), with FodHV2 grouping in the "Betahypovirus" clade (Figure 5). Similar topology was observed in trees constructed with aa sequences of $\mathrm{RdRp}$ and helicase domains (Figure $4 \mathbf{B}$ ). 
A UGT domain

BcHV1/HBtom372
CHV3/GH2
CHV4/SR2
PlHV1/ME711
SsHV1/SZ150
StHV1/28A
VCHV1/MVC86
FodHV2/408

BcHV1/HBtom 372 CHV3/GH2

CHV4/SR2

P1HV1/ME711

SsHV1/SZ150

SsHV1/SZ15

VCHV1/MVC86

FodHV2/408
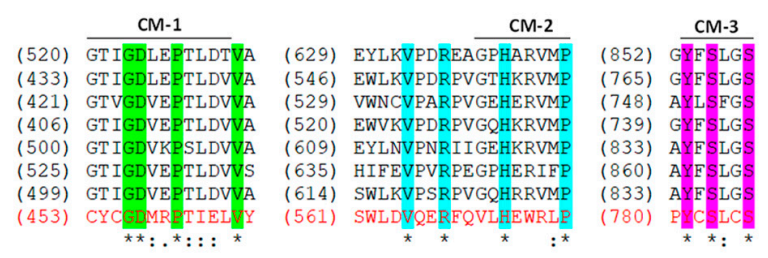

$\mathrm{CM}-4$

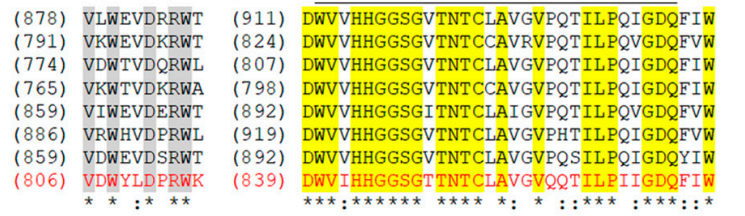

B

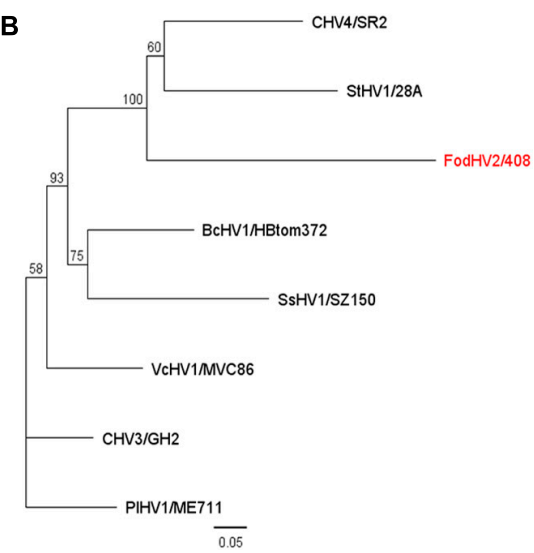

FIGURE 3 | Sequence comparison and phylogenetic tree of the UGT domain of Fusarium oxysporm f. sp. dianthi hypovirus 2 (FodHV2). (A) Multiple alignment of the aa sequence of the UGT domain between FodHV2/408 and selected viruses in the family Hypoviridae [BcHV1/HBtom372, CHV3/GH2, CHV4/SR2, PIHV1/ME711, SsHV1/SZ-150, StHV1/28A, and VcHV1/MVC86 (see Table 2 for complete name and accession number of the hypoviruses)]. Identical residues are indicated with asterisk and color shading; colons and dots indicate conserved and semi-conserved aa residues. CM: conserved motif sequences (1-4) of the UDP-glucosyltransferases superfamily. The alignements were performed using CLUSTALW with the program MAFFT v7. (B) Phylogenetic analysis based on the aa sequence of the UGT domain of FodHV2 and the mycoviruses used for the multiple alignment. The phylogenetic tree was constructed using the program Tree View of Geneious 8.1.5 package (Biomatters), and generated by the NJ method, with 1000 bootstrap replicates.

Pairwise comparisons of FodHV2 nt and aa sequences with currently recognized and putative members of the family Hypoviridae revealed the highest homology with CHV4/SR2 and StHV1/28A (Table 3).

\section{Incidence of FodHV2 Infections in the Collection of $F$. oxysporum $f$. sp. dianthi Isolates Analyzed}

Initially, two dsRNA elements (dsRNA-1 and dsRNA-2) with comparable electrophoretic migration rates were detected in isolates Fod 408 and Fod 409 of F. oxysporum f. sp. dianthi. Characterization of the dsRNA-1 element of isolate Fod 408 identified it as a genome of FodHV2, a putative new member in the family Hypoviridae. To confirm the identity of the mycovirus detected in isolate Fod 409, the dsRNA purified from this isolate was subjected to RT-PCR amplification using specific primers directed to the RdRp of FodHV2. The $1.2 \mathrm{~kb}$ amplicon obtained was purified from the agarose gel and sequenced. Comparison of this sequence with the corresponding sequence of FodHV2 showed a 100\% identity (Supplementary Figure 2), and therefore indicated that fungal isolate Fod 409 was also infected with hypovirus FodHV2.

Although the rest of isolates analyzed did not show any traces of viral dsRNA in the cellulose column chromatography extracts, all those extracts were also subjected to RT-PCR to discard the possibility of not-observable low-viral load FodHV2 infections. Results obtained indicated that no additional isolates were infected with FodVH2 (not shown).

\section{Biological Effect of FodHV2 on F. oxysporum f. sp. dianthi}

In order to study the possible effect of FodHV2 on its host, we attempted obtaining two isogenic isolates infected and not-infected with FodHV2. In a first attempt, we tried to obtain a virus-free line of the naturally infected isolate Fod 408 by single conidia selection. A total of 40 monoconidial cultures were analyzed by cellulose column chromatography. Agarose gel electrophoresis of the dsRNA extracts showed that all monoconidial cultures were infected with FodHV2 (Supplementary Figure 3). Alternatively, the obtention of isogenic virus-free and virus-infected strains was achieved by passing mycovirus FodHV2 through hyphal anastomosis between the strain originally infected (Fod 408, donor) and another $\mathrm{Hyg}^{\mathrm{R}}$ tagged virus-free strain $\left(\right.$ Fod $77 \mathrm{Hyg}^{\mathrm{R}}$, recipient). As a result, two isogenic strains, not infected $\left(\right.$ Fod $\left.77 \mathrm{Hyg}^{\mathrm{R}}\right)$ and infected (Fod $77 \mathrm{Hyg}^{\mathrm{R}} \mathrm{HV}^{+}$) with mycovirus FodHV2, were obtained (Figure 6).

Effect of FodHV2 on host growth on solid medium and conidiation rate in liquid medium was estimated by comparison of both Fod $77 \mathrm{Hyg}^{\mathrm{R}}$ and Fod $77 \mathrm{Hyg}^{\mathrm{R}} \mathrm{HV}^{+}$isolates. Results obtained showed that neither the morphology and radial growth rate on solid medium, nor the conidiation rate in liquid medium, were significantly affected by the FodVH2infection (Figure 6).

To determine the effect of FodHV2 on virulence, two pathogenicity tests were performed in which several susceptible carnation cultivars were inoculated with each Fod $77 \mathrm{Hyg}^{\mathrm{R}}$ and Fod $77 \mathrm{Hyg}^{\mathrm{R}} \mathrm{HV}^{+}$strains. Factorial analysis of the disease data showed that there were no significant differences $(P \leq 0.05)$ between the sAUDPC percentages obtained with all the susceptible carnation cultivars and the two inoculated strains (Table 4). Fungal isolation assays performed with representatives of plants inoculated with either Fod $77 \mathrm{Hyg}^{\mathrm{R}}$ or Fod $77 \mathrm{Hyg}^{\mathrm{R}} \mathrm{HV}^{+}$showed in both cases an extensive colonization of the plants vascular-system (Supplementary Figure 4). Purification of the dsRNA extracts obtained 


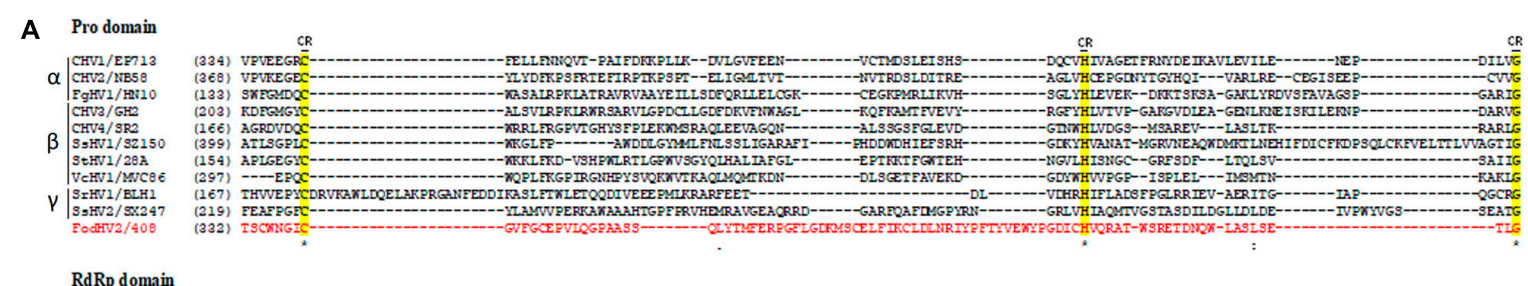

RdRp domain
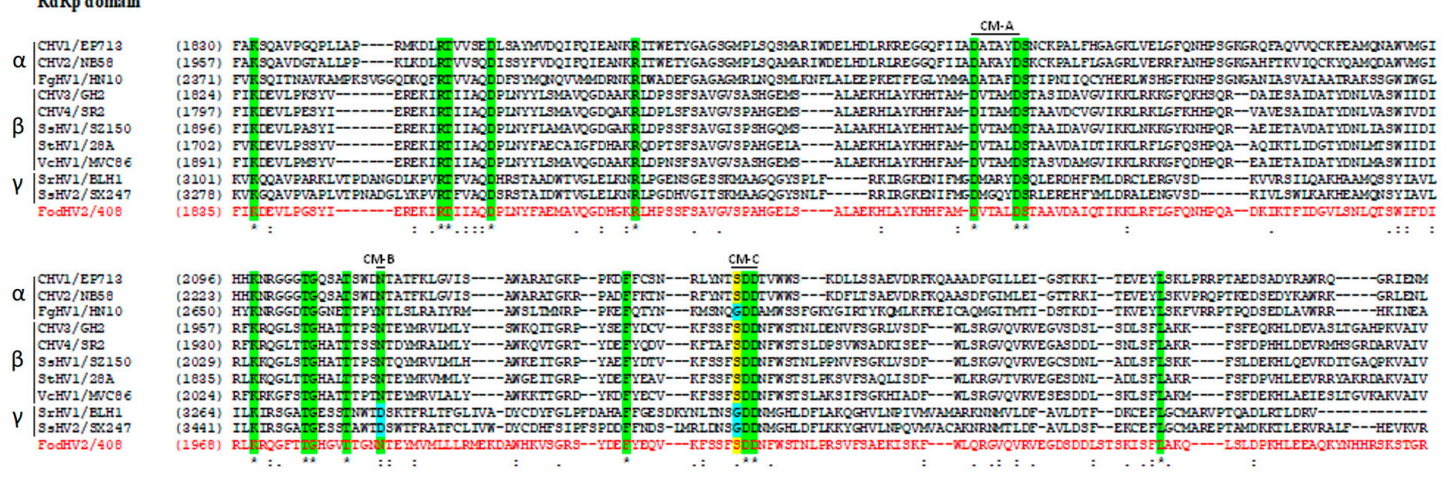

Hel domain
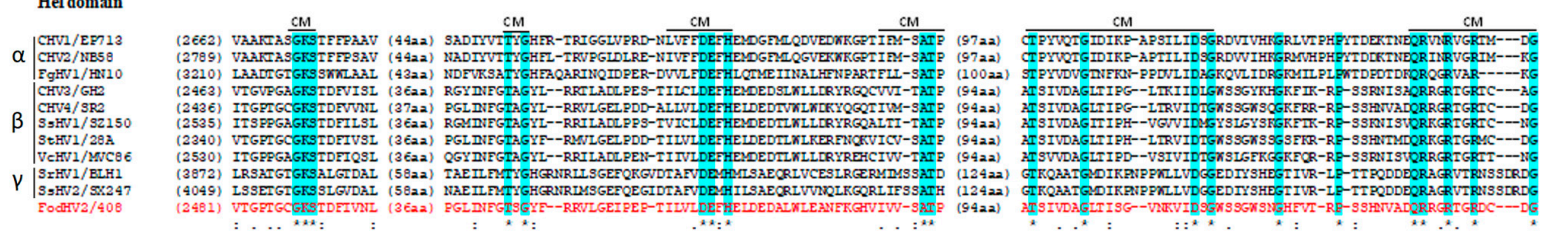

B
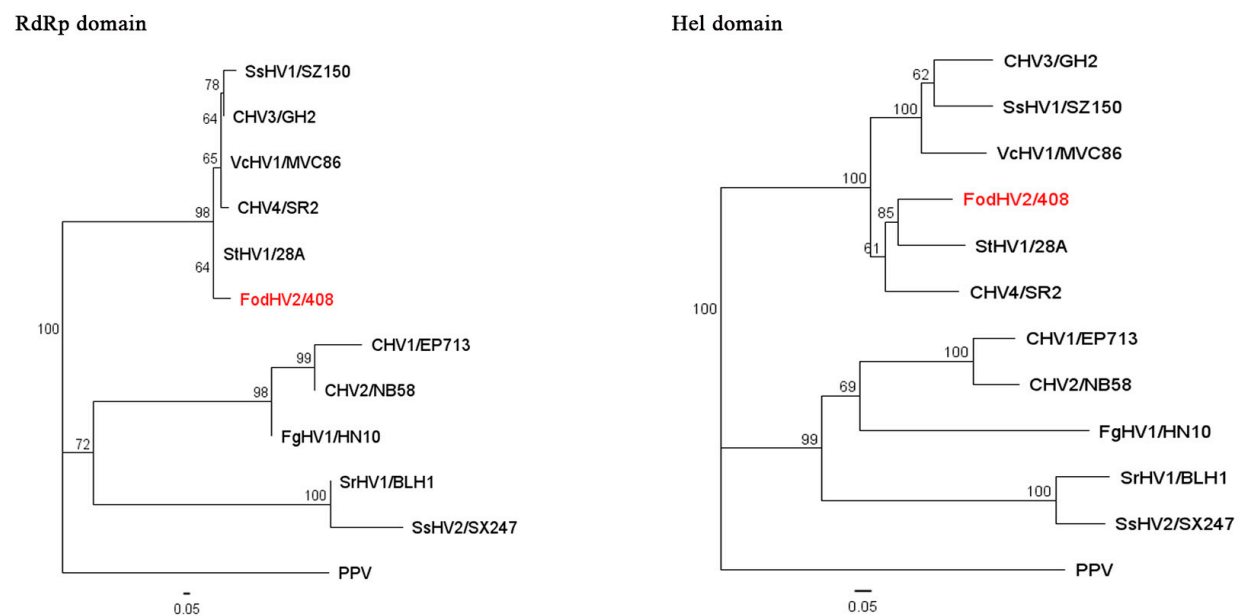

FIGURE 4 | Alignments and phylogenetic trees of the Prot, RdRp, and Hel domains of Fusarium oxysporm f. sp. dianthi hypovirus 2 (FodHV2). (A) Multiple alignments of the aa sequences of the protease (Pro), RNA dependent RNA polimerase (RdRp), and helicase (Hel) domains of FodHV2/408 and selected viruses in the family Hypoviridae (see Table $\mathbf{3}$ for acronym, complete name, and GenBank accesion number of the hypoviruses used in this analysis). Alignments were performed using CLUSTALW with the program MAFFT V7. Identical residues are indicated with asterisk and color shaded; colons and dots indicate conserved and semi-conserved aa residues, respectively. Conserved residues (CR) and conserved motifs (CM) characteristic of each domain are indicated with a black line and his acronym. (B) Phylogenetic trees based on the RdRp and Hel aa sequences of FodHV2/408 and the selected hypoviruses. Phylogenetic trees were constructed using the program Tree View of Geneious 8.1.5 package (Biomatters), and generated by the NJ method with 1000 bootstrap replicates. Plum pox virus (PPV) was used as an out-group.

by cellulose column chromatography from the re-isolated colonies confirmed the presence of FodHV2 in isolate Fod $77 \mathrm{Hyg}^{\mathrm{R}} \mathrm{HV}^{+}$, and its absence in the case of isolate Fod $77 \mathrm{Hyg}^{\mathrm{R}}$ (Supplementary Figure 4).

\section{DISCUSSION}

In this study we have molecularly and biologically characterized a novel mycovirus identified in isolate Fod 408 of Fusarium 


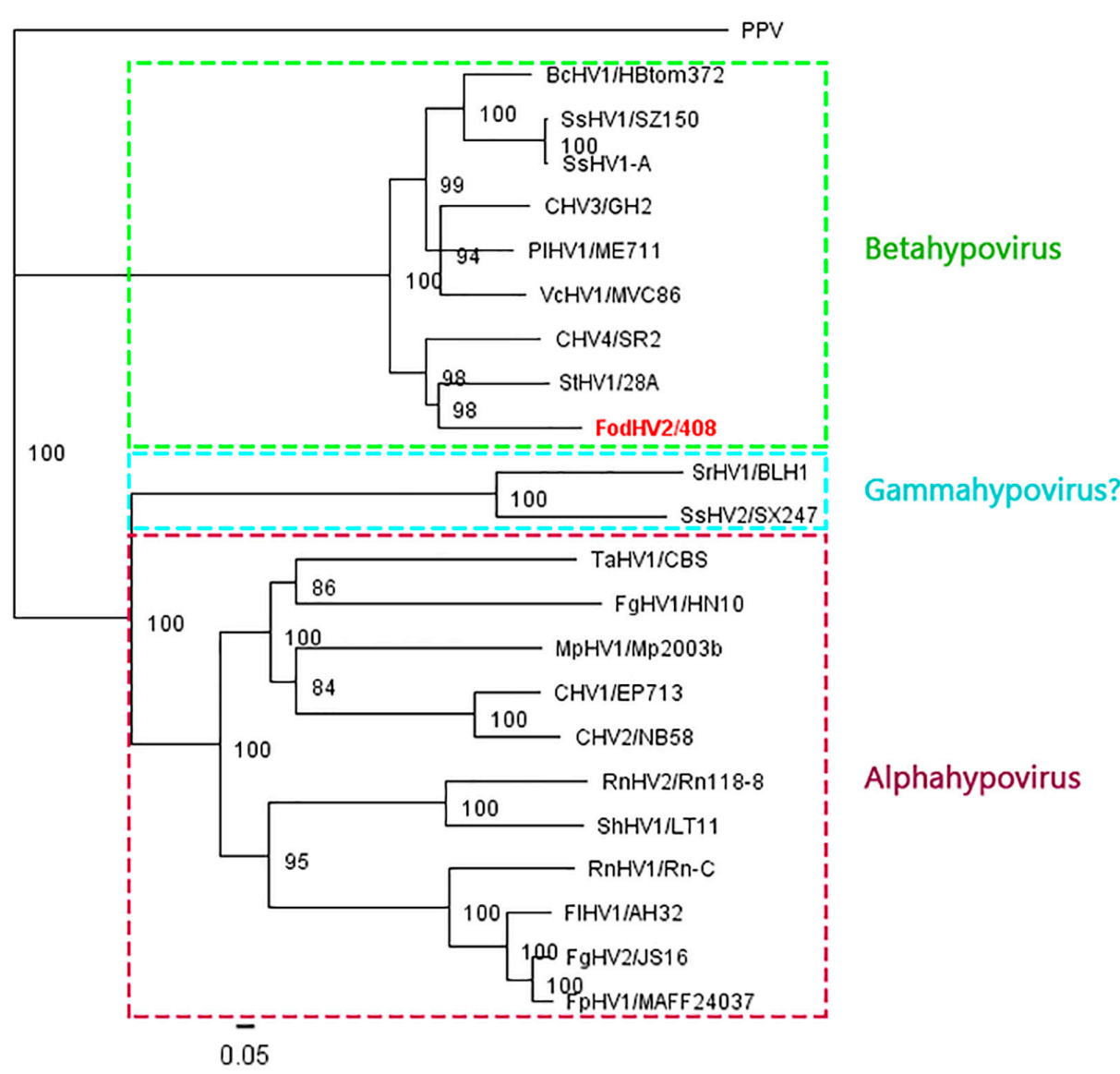

FIGURE 5 | Phylogenetic analysis of Fusarium oxysporm f. sp. dianthi hypovirus 2 (FodHV2) based on the aa sequence of the polyprotein. Neighbor-Joining consensus tree of FodHV2/408 and all the other hypoviruses [Botrytis cinerea hypovirus 1 (BcHV1/HBtom372; accession no. MG554632), Sclerotinia sclerotiorum hypovirus 1 (SsHV1/SZ-150; accession no. AEL99352), Sclerotinia sclerotiorum hypovirus 1-A (SsHV1-A; accession no. AWY10948), Chryphonectria hypovirus 3 (CHV3/GH2; accession no. AF188515), Phomopsis longicolla hypovirus 1 (PIHV1/ME711; accession no. KF537784), Valsa ceratosperma hypovirus 1 (VCHV1/MVC86; accession no. AB690372), Chryphonectria hypovirus 4 (CHV4/SR2; accession no. AY307099), Setosphaeria turcica hypovirus 1 (StHV1/28A; accession no. MK279474), Sclerotium rolfsii hypovirus (SrHV1/BLH1; accession no. AZA15168), Trichoderma asperellum hypovirus 1 (TaHV1/CBS; accession no. MK279475), Sclerotinia sclerotiorum hypovirus 2 (SsHV2/SX247; accession no. AlA61616), Fusarium graminearum hypovirus 1 (FgHV1/HN10; accession no. AZT88611), Macrophomina phaseolina hypovirus 1 (MpHV1/Mp2003b; accession no. ALD89099), Chryphonectria hypovirus 1 (CHV1/EP713; accession no. M57938), Chryphonectria hypovirus 2 (CHV2/NB58; accession no. L29010), Rosellinia necatrix hypovirus 1 (RnHV1/Rn-C; accession no. PRJNA485481), Rosellinia necatrix hypovirus 2 (RnHV1/Rn118-8; accession no. BBB86776), Sclerotinia homoeocarpa hypovirus 1 (ShHV1/LT11; accession no. MK279473), Fusarium langsethiae hypovirus 1 (FIHV1/AH32; accession no. YP_009330037), Fusarium graminearum hypovirus 2 (FgHV2/JS16; accession no. PRJNA485481), Fusarium poae hypovirus 1 (FpHV1/MAFF24037; accession no. BAV56305), and the plant potyvirus Plum pox virus (PPV) as an out-group] based on the full length aa sequence of the viral polyprotein. The color boxes indicate the different proposed genera of "Alphahypovirus," "Betahypovirus," and "Gammahypovirus." The phylogenetic tree was constructed using Tree View of Geneious 8.1.5 package (Biomatters), and generated by the NJ method with 1000 bootstrap replicates.

oxysporum f. sp. dianthi. The complete viral genome is 9,444 nt long, excluding the poly(A) tail, and comprises a 309-nt $5^{\prime}$-UTR, an 8,679-nt single ORF encoding a polyprotein of 2,892 aa residues and $268 \mathrm{kDa}$, and a 456-nt $3^{\prime}$-UTR. The polyprotein contains three highly conserved domains of UGT, RdRp, and helicase. In addition, identification of conserved Cys, Hys, and Gly residues in the N-terminal region of the polyprotein suggests the presence of a catalytic site of a highly diverged protease. Homology searches revealed a high sequence similarity with the polyprotein of other mycoviruses in the genus Hypovirus; this similarity extended also to the $5^{\prime}$ - and $3^{\prime}$-UTR regions. Based on these results, we propose that this virus is a novel member of the family Hypoviridae, for which we propose the name Fusarium oxysporum f. sp. dianthi hypovirus 2 (FodHV2).

Members of all four currently recognized species in the genus Hypovirus were isolated from C. parasitica (Hillman et al., 1990, 1992, 1994; Enebak et al., 1994; Smart et al., 1999; LinderBasso et al., 2005; Nuss and Hillman, 2011), but a number of unclassified hypovirus-like viruses have been described infecting other filamentous fungi, e.g., Agaricus bisporus (Deakin et al., 2017), Alternaria alternata (Li et al., 2019), Macrophomina phaseolina (Marzano et al., 2016), Phomopsis longicolla (Koloniuk et al., 2014), Sclerotinia sclerotiorum (Xie et al., 2011; Hu et al., 2014; Khalifa and Pearson, 2014; Marzano et al., 2015), and Valsa ceratosperma (Yaegashi et al., 2012). The only four possible 
TABLE 3 | Nucleotide and amino acid identities between FodHV2 and other mycoviruses in the family Hypoviridae.

\begin{tabular}{|c|c|c|c|c|c|c|c|c|c|c|c|}
\hline & \multirow[t]{2}{*}{ Virus $^{a}$} & \multirow[t]{2}{*}{ Acronym } & \multicolumn{2}{|c|}{ Full sequence } & \multicolumn{2}{|c|}{$\begin{array}{l}\text { Non-coding } \\
\text { region }(n t \%)^{b}\end{array}$} & \multicolumn{4}{|c|}{ Coding region $(\mathrm{aa} \%)^{\mathrm{c}}$} & \multirow[t]{2}{*}{ Accesion no } \\
\hline & & & $\mathbf{N t} \%$ & $\mathrm{Aa} \%$ & $5^{\prime}$ & $3^{\prime}$ & Pro & UGT & RdRp & Hel & \\
\hline \multirow[t]{3}{*}{$\alpha$} & Cryphonectria hypovirus 1 & CHV1/EP713 & 29 & $8^{d}$ & 28 & 25 & $10^{\mathrm{e}}$ & $--^{f}$ & 14 & 21 & M57938 \\
\hline & Cryphonectria hypovirus 2 & $\mathrm{CHV} 2 / \mathrm{NB} 58$ & 28 & $8^{d}$ & 28 & 28 & 11 & $--^{f}$ & 12 & 21 & L29010 \\
\hline & Fusarium graminearum hypovirus 1 & $\mathrm{FgHV} 1 / \mathrm{HN} 10$ & 28 & $7^{d}$ & 27 & 27 & 10 & $-{ }^{f}$ & 13 & 20 & AZT88611 \\
\hline \multirow[t]{5}{*}{$\beta$} & Cryphonectria hypovirus 3 & $\mathrm{CHV} 3 / \mathrm{GH} 2$ & 46 & 41 & 39 & 26 & 16 & 47 & 65 & 55 & AF188515 \\
\hline & Cryphonectria hypovirus 4 & CHV4/SR2 & 49 & 47 & 49 & 29 & 17 & 51 & 66 & 64 & AY307099 \\
\hline & Sclerotinia sclerotiorum hypovirus 1 & SsHV1/SZ150 & 44 & 39 & 28 & 30 & 14 & 42 & 64 & 52 & JF781304 \\
\hline & Setosphaeria turcica hypovirus 1 & StHV1/28A & 48 & 46 & 50 & 30 & 10 & 47 & 72 & 69 & JF781304 \\
\hline & Valsa ceratosperma hypovirus 1 & VcHV1/MVC86 & 49 & 43 & 38 & 24 & 16 & 49 & 66 & 58 & AB690372 \\
\hline \multirow[t]{2}{*}{$\gamma$} & Sclerotium rolfsii hypovirus 1 & SrHV1/BLH1 & 27 & 7 & 22 & 28 & 6 & $-^{f}$ & 12 & 14 & $\mathrm{MH037014}$ \\
\hline & Sclerotinia sclerotiorum hypovirus 2 & SsHV2/SX247 & 24 & 7 & 28 & 27 & 10 & $-{ }^{f}$ & 11 & 13 & KJ561218 \\
\hline
\end{tabular}

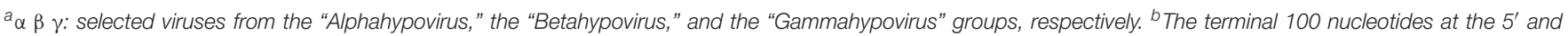

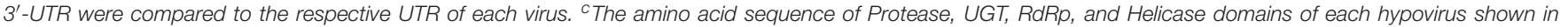

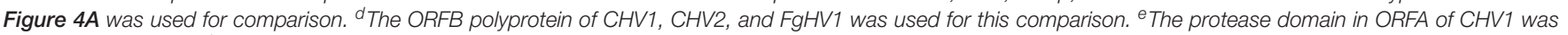
used for comparison. ${ }^{f}$ No UGT domain was detected in the polyprotein of CHV1, CHV2, FgHV1, SrHV1 and SsHV2.

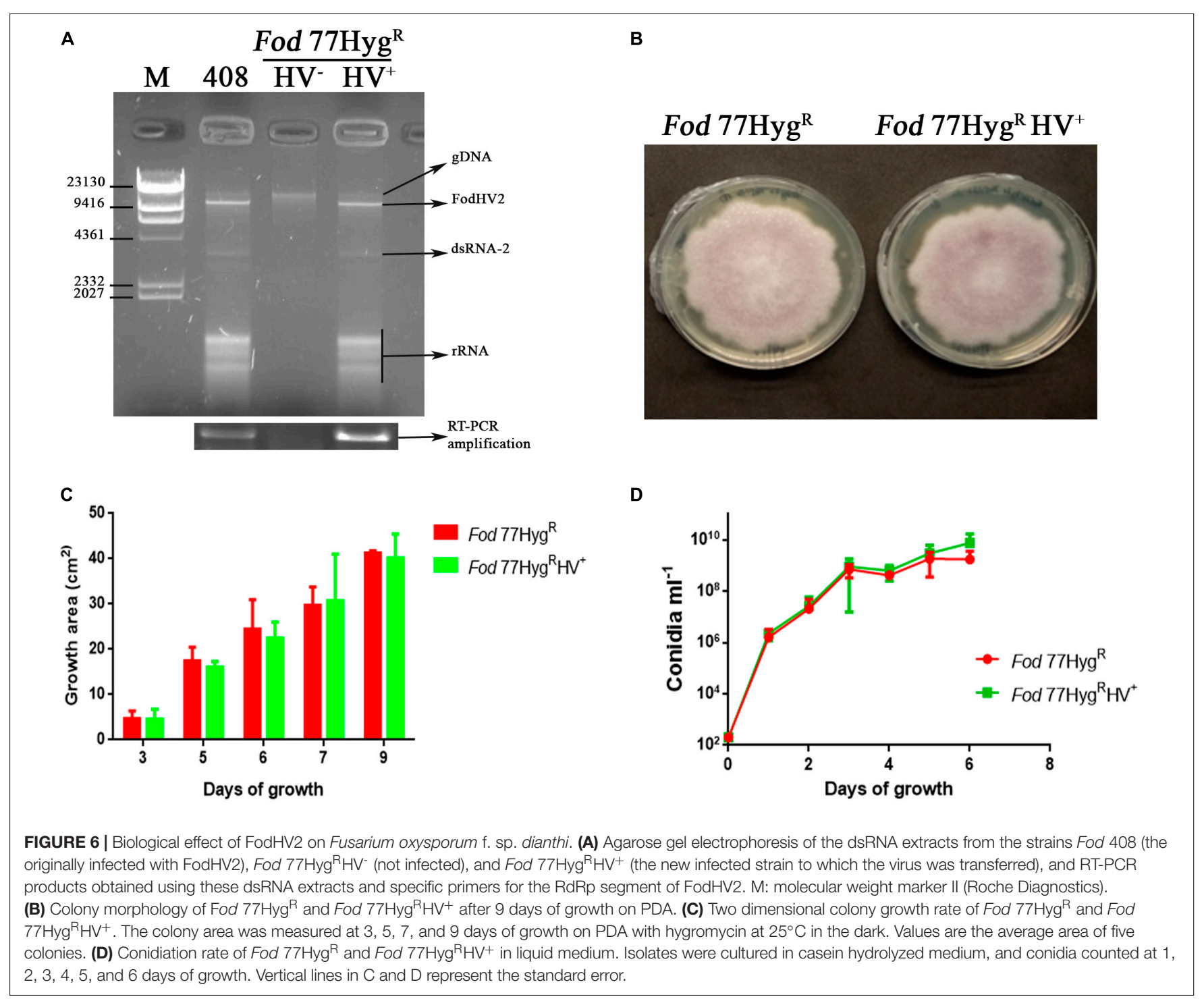


TABLE 4 | Percentage of the standardized area under the disease progress curve (sAUDPC)y.

Carnation cultivar

\begin{tabular}{|c|c|c|c|c|c|c|}
\hline \multirow[t]{2}{*}{ Test date } & \multirow[t]{2}{*}{ Isolate inoculated } & \multicolumn{4}{|c|}{ Susceptible } & \multirow{2}{*}{$\frac{\text { Resistant }}{\text { Galaxia }}$} \\
\hline & & Candela & Baltico & Master & Pink Bijou & \\
\hline & Fod $77 \mathrm{Hyg}^{\mathrm{R}} \mathrm{HV}^{+}$ & $0.887^{a}$ & $0.735^{b}$ & $0.700^{\circ}$ & $0.990^{d}$ & 0 \\
\hline \multirow[t]{2}{*}{ April 2017} & Fod $77 \mathrm{Hyg}^{\mathrm{R}}$ & $0.427^{\mathrm{a}}$ & $0.417^{\mathrm{ab}}$ & $0.533^{\mathrm{bc}}$ & $0.848^{d}$ & 0 \\
\hline & Fod $77 \mathrm{Hyg}^{\mathrm{R}} \mathrm{HV}^{+}$ & $0.328^{a}$ & $0.552^{\mathrm{b}}$ & $0.551^{\mathrm{bc}}$ & $0.848^{d}$ & 0 \\
\hline
\end{tabular}

${ }^{y}$ Means followed by the same letter in each test date are not significantly different according to Fisher's least significant difference (LSD) (P $\left.\leq 0.05\right)$.

members of the family Hypoviridae described from Fusarium species are FgHV1 and FgHV2 from F. graminearum (Wang et al., 2013; Li et al., 2015), FlHV1 from F. langsethiae (Li et al., 2017), and FpHV2 from F. poae (Osaki et al., 2016). In this work we have detected FodHV2 in a strain of F. oxysporum $\mathrm{f}$. sp. dianthi. Therefore, FodHV2 is the first hypovirus described infecting the important plant pathogenic species F. oxysporum. Another unique feature of FodVH2 is that it has been detected infecting isolate Fod 408 obtained from a symptomatic carnation plant sampled in Morocco. Therefore, it is the first hypovirus described in the African continent.

Based on differences in the genomic organization and on results from phylogenetic analyses, Yaegashi et al. (2012) proposed the distinction of two genera within the family Hypoviridae: the genus "Alphahypovirus," represented by $\mathrm{CHV} 1$ and CHV2, and the genus "Betahypovirus," represented by $\mathrm{CHV} 3$ and $\mathrm{CHV} 4$. The successive description of newly proposed members in this family has supported this reorganization of the family, since the majority of the novel mycoviruses identified could be assigned to either of the two proposed genera. Exceptions are Sclerotinia sclerotium hypovirus 2 (SsHV2, isolates 5472 and SX247) and Sclerotium rolfsii hypovirus 1 (SrHV1/AZA15168), the only three hypoviruses that do not fit in the "Alpha-" or "Beta-hypovirus" genera, and for which a creation of a new genus ("Gammahypovirus") has been recently proposed ( $\mathrm{Hu}$ et al., 2014). Genome length, genomic organization, and phylogenetic analysis, clearly indicate that FodHV2 could be assigned to the "Betahypovirus" group. As in other possible members in that putative genus, genome of FodHV2 is shorter than that of the members in the Alphaor Gamma- groups, and contains a single ORF. The encoded polyprotein includes protease, RdRp, and helicase domains, characteristic of all hypoviruses, but also contains a distinctive UGT domain which is encoded solely by the members of the "Betahypovirus" group (Yaegashi et al., 2012; Gilbert et al., 2019). In addition, viruses in the putative genus "Betahypovirus" share sequence conservation in the $5^{\prime}$-UTR, including a 15 nt sequence (CTGGTTTATACTCTG) present in all known putative betahypoviruses (Gilbert et al., 2019). The comparison of the complete nt and aa sequences between FodHV2 and other mycoviruses in the family Hypoviridae showed the greatest similarity with the betahypoviruses CHV4 (49 and 47\%, respectively), and StHV1 (48 and 46\%, respectively). Similar results were obtained when single functional domains were used for comparisons. Multiple alignments of the UGT, RdRp, and Hel domains between FodHV2 and other hypoviruses, allowed the identification of a number of conserved motifs. Alignments for the UGT aa sequence identified the four conserved motifs (CM1 to 4) characteristic of UDP-glucosyltransferases (Warnecke et al., 1999) which are present in betahypoviruses, but not in alpha- or gammahypoviruses. Multiple alignments of the RdRp domain identified the motifs A (D-D), B (N), and C (SDD/GDD) characteristic of viral RdRps (Hansen et al., 1997; O'Reilly and Kao, 1998; Gohara et al., 2000). Particularly, the presence of tripeptide SDD constituting "motif C" has been described for most of the Hypoviridae members. Interestingly, the presence of a $\mathrm{D}$ residue instead of an $\mathrm{N}$ residue in motif $\mathrm{B}$ seems to differentiate gammahypoviruses from alpha- or betahypoviruses. Finally, multiple alignments of the Hel domain identified six out of the eight conserved motifs representative of the DEAD, DEAH and DEXH boxes, which are characteristic of RNA helicases in the Superfamily II (Linder et al., 1989). As previously noted with other hypoviruses (Yaegashi et al., 2012), homology among the Prot domain showed to be lower (between 6 and 17\%) than those obtained with the UGT, RdRp, or Hel domains. Contrary to the alphahypoviruses that contain active proteases in each ORF, members of the "Betahypovirus" group seem not to have an active protease, because only the catalytic residues of Cys, Hys, and Gly could be identified in the alignments (Koonin et al., 1991; Hillman et al., 1994; Smart et al., 1999). Phylogenetic analyses based on the full-length aa sequence of the viral polyprotein, or on the sequence of each RdRp, and Hel protein domains, all clustered FodHV2 with the members of the "Betahypovirus" group.

In order to analyze the putative effect on its fungal host, we transferred FodHV2 from the original infected strain Fod 408 (donor) to another virus-free strain (recipient) by hyphal anastomosis (horizontal transmission). Strain Fod 77 was selected as a recipient in the first instance taking advantage of the fact that it was already transformed with a hygromicin resistance gene (Fod 77 $\mathrm{Hyg}^{\mathrm{R}}$ ) (Lemus-Minor et al., 2019). However, strains Fod 408 and Fod 77 had been molecularly identified as a race 2 molecular group II isolate (this work), and a race 2 molecular group I isolate (Gómez-Lama Cabanás et al., 2012), respectively. As previously determined (Gómez-Lama Cabanás and Pérez-Artés, 2014), F. oxysporum f sp. dianthi 
isolates of these two race-molecular groups belong to different vegetative compatibility groups (VCGs) and therefore should be vegetatively incompatible. Despite the expected incompatibility, FodHV2 was successfully transferred from isolate Fod 408 to isolate Fod $77 \mathrm{Hyg}^{\mathrm{R}}$. Additionally, many of the Fod $77 \mathrm{Hyg}^{\mathrm{R}}$ colonies analyzed for the presence of FodHV2 also showed the presence of the dsRNA-2 segment, although the accumulation of this dsRNA varied notably among colonies. In most filamentous fungi, the heterogenic incompatibility acts as a barrier to prevent the spread of mycoviruses (Caten, 1972; Esser, 2006), but mycoviruses may occasionally escape from this barrier system. For example, in C. parasitica some of the hypoviruses could be transmitted in particular incompatible combinations (Cortesi et al., 2001; Biella et al., 2002; Choi et al., 2012), which suggests that the timing or strength of the programed cell death associated to heterogenic incompatibility can be different for different combinations of vic (vegetative incompatible) genes. Moreover, the compatibility between isolates belonging to different VCGs has been described for different formae speciales of F. oxysporum, including F. oxysporum f. sp. dianthi (Gómez-Lama Cabanás and Pérez-Artés, 2014). Fungal isolates showing compatibility with others that belong to different VCG can be considered as "bridge" isolates, and might represent intermediates toward the formation of "new" VCGs (Katan et al., 1991; Cai et al., 2003). Taking this into account, isolates Fod 408 and/or Fod 77 could be considered one of these "bridge" isolates. This hypothesis would be supported by the fact that FodHV2 has also been detected infecting isolate Fod 409, another isolate from Morocco that, interestingly, belongs to a different race and VCG than Fod 408.

Along with the facility to transfer horizontally, the transmission of FodHV2 through the conidia (vertical transmission) proved highly efficient. During the initial attempt to obtain a virus free representative of isolate Fod 408 by single conidia selection, we obtained a total of 40 single-conidia cultures that were all infected with FodHV2. In addition, a similar analysis with the new infected isolate Fod $77 \mathrm{Hyg}^{\mathrm{R}} \mathrm{HV}^{+}$also showed $100 \%$ efficiency in the vertical transmission of the virus.

Comparison of isogenic strains Fod $77 \mathrm{Hyg}^{\mathrm{R}}$ (not infected) and Fod $77 \mathrm{Hyg}^{\mathrm{R}} \mathrm{HV}^{+}$(infected) showed that FodHV2 did not affect the vegetative growth, the conidiation, or the virulence of the F. oxysporum f. sp. dianthi infected strain. Additionally, results from fungal isolation assays performed with representatives of inoculated carnation plants indicated that both the virus-free Fod $77 \mathrm{Hyg}^{\mathrm{R}}$ and the virus-infected $77 \mathrm{Hyg}^{\mathrm{R}} \mathrm{HV}^{+}$isolates had a similar capacity to colonize the vascular system of the plant. Mycoviruses in the family Hypoviridae were initially associated with the induction of hypovirulence and/or the alteration of the vegetative growth in their hosts, but successive identification of new representatives in this family evidenced a cryptic nature in some of them. The "Alphahypovirus" and "Betahypovirus" proposed genera in that family include both viruses that alter phenotypic characters including virulence, and viruses with no apparent effect on the host. In this regard, it is interesting to mention that hypoviruses CHV4/SR2 and VcHV1/MVC86, two of the most molecularly similar to FodHV2, are also viruses with no visible effect on its fungal host (Linder-Basso et al., 2005; Yaegashi et al., 2012).
Along with the FodHV2 dsRNA, the presence of another shorter molecule was detected in isolate Fod 408. Partial sequence analysis of that dsRNA-2 showed a variable nt identity exclusively with the corresponding nt sequences of FodHV2, but the exact nature of this dsRNA has not been confirmed. The presence of both the complete hypovirus-dsRNA and another, possibly defective-dsRNA has been described for other betahypoviruses, e.g., AaHV1 (Li et al., 2019), BcHV1 (Hao et al., 2018), CHV3/GH2 (Smart et al., 1999), and SsHV1/SZ150 (Xie et al., 2011). In some cases (SsHV1/SZ150), data obtained suggested a contribution of the defective dsRNA to the induction of hypovirulence, but not in others (AaHV1, BcHV1). In the case of FodHV2, the joint presence of both dsRNAs had no effect on mycelial growth, conidiation, or virulence. Nevertheless, more work is needed to determine the exact nature of the dsRNA-2 molecule and its possible interference (positive or negative) on the potential effect of FodHV2 on its host.

\section{DATA AVAILABILITY STATEMENT}

The datasets generated for this study can be found in the NCBI, GenBank, Accession No. MN176979.

\section{AUTHOR CONTRIBUTIONS}

EP-A, MC, MG-P, and AT-T conceived and designed the experiments. AT-T performed the sequencing, assembly, analysis of the sequence, phylogenetic analyses, and phenotypic analysis. $\mathrm{MC}$ and MG-P obtained the Hyg ${ }^{\mathrm{R}}$-tagged Fod strain. EP-A and AT-T analyzed the data and wrote the manuscript.

\section{FUNDING}

This research was supported by Grants AGL 2013-48980-R from the Spanish Ministry of Economy and Competitiveness and AGL 2016-80048-R from the Spanish Ministry of Science and Innovation, co-funded by the European Union (FEDER funds). We acknowledge support of the publication fee by the CSIC Open Access Publication Support initiative through its Unit of Information Resources for Research (URICI).

\section{ACKNOWLEDGMENTS}

We thank Antonio Valverde and Carlos Casanova for their valuable technical assistance and Emilio A. Cano (Barberet \& Blanc S.A., Dümmen Orange) for providing carnation cultivars.

\section{SUPPLEMENTARY MATERIAL}

The Supplementary Material for this article can be found online at: https://www.frontiersin.org/articles/10.3389/fmicb.2019. 03131/full\#supplementary-material 


\section{REFERENCES}

Arjona-Lopez, J. M., Telengech, P., Jamal, A., Hisano, S., Kondo, H., Yelin, M. D., et al. (2018). Novel, diverse RNA viruses from Mediterranean isolates of the phytopathogenic fungus, Rosellinia necatrix: insights into evolutionary biology of fungal viruses. Environ. Microbiol. 20, 1464-1483. doi: 10.1111/1462-2920. 14065

Baayen, R. P., van Dreven, F., Krijger, M. C., and Waalwijk, C. (1997). Genetic diversity in Fusarium oxysporum f. sp.dianthi and Fusarium redolens f. sp. dianthi. Eur. J. Plant Pathol. 103, 395-408. doi: 10.1094/PHYTO.2001.91.11. 1037

Biella, S., Smith, M. L., Aist, J. R., Cortesi, P., and Milgroom, M. G. (2002). Programmed cell death correlates with virus transmission in a filamentous fungus. Proc. Biol. Sci. 269, 2269-2276. doi: 10.1098/rspb.2002.2148

Cai, G., Gale, L. R., Schneider, R. W., Kistler, H. C., Davis, R. M., Elias, K. S., et al. (2003). Origin of race 3 of Fusarium oxysporum f. sp. lycopersici at a single site in California. Phytopathology 93, 1014-1022. doi: 10.1094/PHYTO.2003.93.8. 1014

Caten, C. E. (1972). Vegetative incompatibility and cytoplasmic infection in fungi. J. Gen. Microbiol. 72, 221-229. doi: 10.1099/00221287-72-2-221

Chiba, S., Salaipeth, L., Lin, Y.-H., Sasaki, A., Kanematsu, S., and Suzuki, N. (2009). A novel bipartite double-stranded RNA mycovirus from the white root rot fungus Rosellinia necatrix: molecular and biological characterization, taxonomic considerations, and potential for biological control. J. Virol. 83, 12801-12812. doi: 10.1128/JVI.01830-09

Choi, G. H., Dawe, A. L., Churbanov, A., Smith, M. L., Milgroom, M. G., and Nuss, D. L. (2012). Molecular characterization of vegetative incompatibility genes that restrict hypovirus transmission in the chestnut blight fungus Cryphonectria parasitica. Genetics 190, 113-127. doi: 10.1534/genetics.111.133983

Cortesi, P., McCulloch, C. E., Song, H., Lin, H., and Milgroom, M. G. (2001). Genetic control of horizontal virus transmission in the chestnut blight fungus, Cryphonectria parasitica. Genetics 159, 107-118.

Deakin, G., Dobbs, E., Bennett, J. M., Jones, I. M., Grogan, H. M., and Burton, K. S. (2017). Multiple viral infections in Agaricus bisporus - Characterisation of 18 unique RNA viruses and 8 ORFans identified by deep sequencing. Sci. Rep. 7:2469. doi: 10.1038/s41598-017-01592-9

Enebak, S. A., MacDonald, W. L., and Hillman, B. I. (1994). Effect of dsRNA associated with isolates of Cryphonectria parasitica from the central Appalachians and their relatedness to other dsRNAs from North America and Europe. Phytopathology 84, 528-534. doi: 10.1094/Phyto-84-528

Esser, K. (2006). "Heterogenic incompatibility in fungi," in The Mycota. I. Growth, differentiation and sexuality, eds U. Kües, and R. Fischer, (Berlin: SpringerVerlag), 141-165. doi: 10.1007/3-540-28135-5_8

Fulbright, D. W. (1984). Effect of eliminating dsRNA in hypovirulent Endothia parasitica. Phytopathology 74, 722-724.

Garibaldi, A., and Gullino, M. L. (1987). Attempts of biocontrol of Fusarium-wilt of carnation in Italy. Phytopathology 77, 1721-1721.

Ghabrial, S. A., and Suzuki, N. (2009). Viruses of plant pathogenic fungi. Annu. Rev. Phytopathol. 47, 353-384. doi: 10.1146/annurev-phyto-080508-081932

Gilbert, K. B., Holcomb, E. E., Allscheid, R. L., and Carrington, J. C. (2019). Discovery of new mycoviral genomes within publicly available fungal transcriptomic datasets. bioRxiv [Preprint]. doi: 10.1101/510404

Gohara, D. W., Crotty, S., Arnold, J. J., Yoder, J. D., Andino, R., and Cameron, C. E. (2000). Poliovirus RNA-dependent RNA polymerase (3Dpol): structural, biochemical, and biological analysis of conserved structural motifs A and B. J. Biol. Chem. 275, 25523-25532. doi: 10.1074/jbc.M00267 1200

Gómez-Lama Cabanás, C., and Pérez-Artés, E. (2014). New evidence of intra-race diversity in Fusarium oxysporum $f$. sp. dianthi populations based on Vegetative Compatibility Groups. Eur. J. Plant Pathol. 139, 445-451. doi: 10.1007/s10658014-0412-y

Gómez-Lama Cabanás, C., Valverde-Corredor, A., and Pérez-Artés, E. (2012). Molecular analysis of Spanish populations of Fusarium oxysporum f. sp dianthi demonstrates a high genetic diversity and identifies virulence groups in races 1 and 2 of the pathogen. Eur. J. Plant Pathol. 132, 561-576. doi: 10.1007/s10658011-9901-4

Hansen, J. L., Long, A. M., and Schultz, S. C. (1997). Structure of the RNAdependent RNA polymerase of poliovirus. Structure 5, 1109-1122. doi: 10.1016/ S0969-2126(97)00261-X
Hao, F., Ding, T., Wu, M., Zhang, J., Yang, L., Chen, W., et al. (2018). Two novel hypovirulence-associated mycoviruses in the phytopathogenic fungus Botrytis cinerea: Molecular characterization and suppression of infection cushion formation. Viruses 10:254. doi: 10.3390/v10050254

Hillman, B. I., Foglia, R., and Yuan, W. (2000). Satellite and defective RNAs of Cryphonectria hypovirus 3-grand haven 2, a virus species in the family Hypoviridae with a single open reading frame. Virology 276, 181-189. doi: 10.1006/viro. 2000.0548

Hillman, B. I., Halpern, B. T., and Brown, M. P. (1994). A viral dsRNA element of the chestnut blight fungus with a distinct genetic organization. Virology 201, 241-250. doi: 10.1006/viro.1994.1289

Hillman, B. I., Heaton, L. A., Hunter, B. G., Modrell, B., and Jackson, A. O. (1990). Structure of the gene encoding the M1 protein of sonchus yellow net virus. Virology 179, 201-207. doi: 10.1016/0042-6822(90)90289-4

Hillman, B. I., Tian, Y., Bedker, P. J., and Brown, M. P. (1992). A north-american hypovirulent isolate of the chestnut blight fungus with european isolate-related dsRNA. J. Gen. Virol. 73, 681-686. doi: 10.1099/0022-1317-73-3-681

Hu, Z., Wu, S., Cheng, J., Fu, Y., Jiang, D., and Xie, J. (2014). Molecular characterization of two positive-strand RNA viruses co-infecting a hypovirulent strain of Sclerotinia sclerotiorum. Virology 464-465, 450-459. doi: 10.1016/j. virol.2014.07.007

Katan, T., Zamir, D., Sarfatti, M., and Katan, J. (1991). Vegetative compatibility groups and subgroups in Fusarium oxysporum f. sp. radicis-lycopersici. Phytopathology 81, 255-262. doi: 10.1094/Phyto-81-255

Katoh, K., and Standley, D. M. (2013). MAFFT multiple sequence alignment software version 7: improvements in performance and usability. Mol. Biol. Evol. 30, 772-780. doi: 10.1093/molbev/mst010

Khalifa, M. E., and Pearson, M. N. (2014). Characterisation of a novel hypovirus from Sclerotinia sclerotiorum potentially representing a new genus within the Hypoviridae. Virology 46, 441-449. doi: 10.1016/j.virol.2014.07.005

Koloniuk, I., El-Habbak, M. H., Petrzik, K., and Ghabrial, S. A. (2014). Complete genome sequence of a novel hypovirus infecting Phomopsis longicolla. Arch. Virol. 159, 1861-1863. doi: 10.1007/s00705-014-1992-8v

Komada, H. (1975). Development of a selective medium for quantitative isolation of Fusarium oxysporum from natural soil. Rev. Plant Protect. Res. 8, 114-124.

Koonin, E. V., Choi, G. H., Nuss, D. L., Shapira, R., and Carrington, J. C. (1991). Evidence for common ancestry of a chestnut blight hypovirulence-associated double-stranded RNA and a group of positive-strand RNA plant viruses. Proc. Natl. Acad. Sci. U.S.A. 88, 10647-10651. doi: 10.1073/pnas.88.23.10647

Lemus-Minor, C. G., Cañizares, M. C., García-Pedrajas, M. D., and Pérez-Artés, E. (2018). Fusarium oxysporum f. sp. dianthi virus 1 accumulation is correlated with changes in virulence and other phenotypic traits of its fungal host. Phytopathology 108, 957-963. doi: 10.1094/PHYTO-06-17-0200-R

Lemus-Minor, C. G., Cañizares, M. C., García-Pedrajas, M. D., and Pérez-Artés, E. (2019). Horizontal and vertical transmission of the hypovirulence-associated mycovirus Fusarium oxysporum f. sp. dianthi virus 1. Eur. J. Plant Pathol. 153, 645-650. doi: 10.1007/s10658-018-1554-0

Li, H., Bian, R., Liu, Q., Yang, L., Pang, T., Salaipeth, L., et al. (2019). Identification of a novel hypovirulence-inducing hypovirus from Alternaria alternata. Front. Microbiol. 10:1076. doi: 10.3389/fmicb.2019.01076

Li, P., Chen, X., He, H., Qiu, D., and Guo, L. (2017). Complete genome sequence of a novel hypovirus from the phytopathogenic fungus Fusarium langsethiae. Genome Announc. 5, e1722-16. doi: 10.1128/genomeA.01722-16

Li, P., Zhang, H., Chen, X., Qiu, D., and Guo, L. (2015). Molecular characterization of a novel hypovirus from the plant pathogenic fungus Fusarium graminearum. Virology 481, 151-160. doi: 10.1016/j.virol.2015.02.047

Linder, P., Lasko, P. F., Ashburner, M., Leroy, P., Nielsen, P. J., Nishi, K., et al. (1989). Birth of the D-E-A-D box. Nature 337, 121-122.

Linder-Basso, D., Dynek, J. N., and Hillman, B. I. (2005). Genome analysis of Cryphonectria hypovirus 4, the most common hypovirus species in North America. Virology 337, 192-203. doi: 10.1016/j.virol.2005.03.038

Marzano, S. L., Nelson, B. D., Ajayi-Oyetunde, O., Bradley, C. A., Hughes, T. J., Hartman, G. L., et al. (2016). Identification of diverse mycoviruses through metatranscriptomics characterization of the viromes of five major fungal plant pathogens. J. Virol. 90, 6846-6863. doi: 10.1128/JVI.00357-16

Marzano, S.-Y. L., Hobbs, H. A., Nelson, B. D., Hartman, G. L., Eastburn, D. M., McCoppin, N. K., et al. (2015). Transfection of Sclerotinia sclerotiorum with in vitro transcripts of a naturally occurring interspecific recombinant 
of Sclerotinia sclerotiorum hypovirus 2 significantly reduces virulence of the fungus. J. Virol. 89, 5060-5071. doi: 10.1128/JVI.03199-14

Melero-Vara, J. M., López-Herrera, C. J., Prados-Ligero, A. M., Vela-Delgado, M. D., Navas-Becerra, J. A., and Basallote-Ureba, M. J. (2011). Effects of soil amendment with poultry manure on carnation Fusarium wilt in greenhouses in southwest Spain. Crop Protect. 30, 970-976. doi: 10.1016/j.cropro.2011.03.022

Milgroom, M. G., and Cortesi, P. (2004). Biological control of chestnut blight with hypovirulence: a critical analysis. Annu. Rev. Phytopathol. 42, 311-338. doi: 10.1146/annurev.phyto.42.040803.140325

Nuss, D. L. (2005). Hypovirulence: mycoviruses at the fungal-plant interface. Nat. Rev. Microbiol. 3, 632-642. doi: 10.1038/nrmicro1206

Nuss, D. L., and Hillman, B. I. (2011). "Hypoviridae," in Virus Taxonomy, eds A. M. Q. King, M. J. Adams, E. B. Carstens, and E. J. Lefkowitz (Oxford: Elsevier), 1029-1034.

O’Reilly, E. K., and Kao, C. C. (1998). Analysis of RNA-dependent RNA polymerase structure and function as guided by known polymerase structures and computer predictions of secondary structure. Virology 252, 287-303. doi: 10.1006/viro.1998.9463

Osaki, H., Sasaki, A., Nomiyama, K., and Tomioka, K. (2016). Multiple virus infection in a single strain of Fusarium poae shown by deep sequencing. Virus Genes. 52, 835-847. doi: 10.1007/s11262-016-1379-x

Pearson, M. N., Beever, R. E., Boine, B., and Arthur, K. (2009). Mycoviruses of filamentous fungi and their relevance to plant pathology. Mol. Plant. Pathol. 10, 115-128. doi: 10.1111/j.1364-3703.2008.00503.x

Saitou, N., and Nei, M. (1987). The neighbor-joining method: a new method for reconstructing phylogenetic trees. Mol. Biol. Evol. 4, 406-425. doi: 10.1093/ oxfordjournals.molbev.a040454

Shapira, R., Choi, G. H., and Nuss, D. L. (1991). Virus-like genetic organization and expression strategy for a double-stranded RNA genetic element associated with biological control of chestnut blight. EMBO J. 10, 731-739. doi: 10.1002/j. 1460-2075.1991.tb08004.x

Smart, C. D., Yuan, W., Foglia, R., Nuss, D. L., Fulbright, D. W., and Hillman, B. I. (1999). Cryphonectria hypovirus 3, a virus species in the family hypoviridae with a single open reading frame. Virology 265, 66-73. doi: 10.1006/viro.1999. 0039

Son, M., Yu, J., and Kim, K. H. (2015). Five questions about mycoviruses. PLoS Pathog. 11:e1005172. doi: 10.1371/journal.ppat.1005172

Suzuki, N., Ghabrial, S. A., Kim, K.-H., Pearson, M., Marzano, S.-Y. L., Yaegashi, H., et al. (2018). ICTV virus taxonomy profile: hypoviridae. J. Gen. Virol. 99, 615-616. doi: 10.1099/jgv.0.001055
Valverde, R. A., Nameth, S. T., and Jordan, R. L. (1990). Analysis of doublestranded-RNA for plant-virus diagnosis. Plant Dis. 74, 255-258.

Velasco, L., Arjona-Girona, I., Ariza-Fernández, M. T., Cretazzo, E., and López-Herrera, C. (2018). A novel hypovirus species from xylariaceae fungi infecting avocado. Front. Microbiol. 9:778. doi: 10.3389/fmicb.2018. 00778

Wang, S., Kondo, H., Liu, L., Guo, L., and Qiu, D. (2013). A novel virus in the family Hypoviridae from the plant pathogenic fungus Fusarium graminearum. Virus Res. 174, 69-77. doi: 10.1016/j.virusres.2013.03.002

Warnecke, D., Erdmann, R., Fahl, A., Hube, B., Muller, F., Zank, T., et al. (1999). Cloning and functional expression of UGT genes encoding sterol glucosyltransferases from Saccharomyces cerevisiae, Candida albicans, Pichia pastoris, and Dictyostelium discoideum. J. Biol. Chem. 274, 13048-13059. doi: 10.1074/jbc.274.19.13048

Xie, J., Wei, D., Jiang, D., Fu, Y., Li, G., Ghabrial, S., et al. (2006). Characterization of debilitation-associated mycovirus infecting the plant-pathogenic fungus Sclerotinia sclerotiorum. J. Gen. Virol. 87, 241-249. doi: 10.1099/vir.0.81 $522-0$

Xie, J., Xiao, X., Fu, Y., Liu, H., Cheng, J., Ghabrial, S. A., et al. (2011). A novel mycovirus closely related to hypoviruses that infects the plant pathogenic fungus Sclerotinia sclerotiorum. Virology 418, 49-56. doi: 10.1016/j.virol.2011. 07.008

Yaegashi, H., Kanematsu, S., and Ito, T. (2012). Molecular characterization of a new hypovirus infecting a phytopathogenic fungus. Valsa ceratosperma. Virus Res. 165, 143-150. doi: 10.1016/j.virusres.2012.02.008

Yuan, W., and Hillman, B. I. (2001). In vitro translational analysis of genomic, defective, and satellite RNAs of Cryphonectria hypovirus 3-GH2. Virology 281, 117-123. doi: 10.1006/viro.2000.0806

Conflict of Interest: The authors declare that the research was conducted in the absence of any commercial or financial relationships that could be construed as a potential conflict of interest.

Copyright $\odot 2020$ Torres-Trenas, Cañizares, García-Pedrajas and Pérez-Artés. This is an open-access article distributed under the terms of the Creative Commons Attribution License (CC BY). The use, distribution or reproduction in other forums is permitted, provided the original author(s) and the copyright owner(s) are credited and that the original publication in this journal is cited, in accordance with accepted academic practice. No use, distribution or reproduction is permitted which does not comply with these terms. 